\title{
Frequency of Peripheral Arterial Disease Diagnosed by Measurement of the Ankle Brachial Index Among Diabetics with No Symptoms of Intermittent Claudication
}

\author{
Sheryll C. Pleo, Jay Vincent J. Cresencio, Elaine B. Alajar \\ Department of Internal Medicine, Manila Doctors Hospital, Philippines
}

\begin{abstract}
Objective. The ankle brachial index (ABI) was measured at rest and after the six-minute walk test (6MWT) to determine the frequency of peripheral arterial disease among diabetics with no symptoms of intermittent claudication.

Methodology. A total of 70 participants were enrolled in the study taken from at the outpatient department of Manila Doctors Hospital and Our Lady of Remedies Health Center, Malate from September to October 2011. Based from the blood pressure resting and after the $6 \mathrm{MWT}, \mathrm{ABI}$ was computed such that a result of $<0.90$ is diagnostic of PAD.
\end{abstract}

Results. Mean age of participants was 60 years $(S D+12.2)$. Among the participants $74 \%$ were females, $63 \%$ were hypertensive, and $14 \%$ were smokers. Systolic and diastolic blood pressure was 140+18.32, $82+12.3$ respectively. Participants who were hypertensive and who smoke was above $30 \%$. ABI classified as non-compressible and borderline was $1.42 \%$ and above $10 \%$ respectively. The frequency of PAD using ABI was $33 \%$ at rest and $37 \%$ after the 6MWT. No severe PAD was seen both resting and after 6MWT.

Conclusion. The frequency of PAD among diabetics with no symptoms of intermittent claudication using $A B I$ seen at the outpatient department of Manila Doctors Hospital and Our Lady of Remedies Health Center was relatively higher after the 6 MWT.

Keywords: ankle-brachial index, diabetes, intermittent claudication, peripheral arterial disease, six-minute walk test

\section{INTRODUCTION}

Peripheral arterial disease (PAD) is an important complication of diabetes mellitus associated with increased morbidity and mortality, strokes and coronary artery disease. ${ }^{1}$ Systemic atherosclerosis is a manifestation associated with increased risk of death and ischemic events. Despite its associations with increased morbidity and mortality, PAD is significantly under-diagnosed and under-treated in the general population.

Lower extremity PAD is a highly prevalent chronic atherosclerotic occlusive disease, estimated to be between $3 \%$ and $10 \%$ worldwide. $^{2}$ In the Western population, the prevalence of PAD with diabetes ranges from $16 \%-22 \% .^{3-4}$ In Asians, $17.7 \%$ diabetics were diagnosed with PAD by ABI. ${ }^{5}$ This can manifest with intermittent claudication and may result in vascular surgery or lower limb amputation. ${ }^{6}$ Lower extremity PAD is a serious disease that affects about $5 \%$ of Filipinos aged 40 years and older. ${ }^{7}$ In a local study by PhilPAD, (2000) done in the National Capital

ISSN 0857-1074

Printed in the Philippines

Copyright $(2012$ by the JAFES

Received June 15, 2012. Accepted October 29, 2012.

This paper was presented in the 2012 17th Philippine Society of Hypertension-PLAS Joint Annual Convention-LRI-Therapharma Dr. Yolando Q.M. Sulit Young Investigator's Award. Ballroom A, Crowne Plaza Galleria Manila Hotel. Oral Presentation.(First Runner-up). February 09, 2012.
Region, $31 \%$ of the population were found to have PAD. ${ }^{8}$ In another local study at the Philippine Heart Center involving 62 patients admitted for coronary angiogram, revealed a data positive for PAD by $\mathrm{ABI}$ measurement was $30.6 \% .{ }^{9}$ Risk factors such as age, race, gender smoking, diabetes, hypertension, dyslipidemia, hyperviscosity and renal insufficiency ${ }^{10}$ all contribute to the occurrence of the disease.

Patients with diabetes have a unique problem with PAD as the disease appears to affect distal blood vessels, which together with superimposed neuropathy, increases patient risk, costs, medication and hospitalization. ${ }^{11}$

The diagnosis of PAD is made from a typical history, physical examination and the ankle -brachial index (ABI) measurement. $\mathrm{ABI}$ is a simple non-invasive screening test that is an inexpensive measure of subclinical atherosclerosis. An ABI $\leq 0.90$ is used to make the diagnosis of PAD and has a sensitivity of $95 \%$ and a specificity of $99 \% .^{12}$ 
The six-minute walk test (6MWT) is a useful measure of functional capacity targeted at people with at least moderately severe impairment. It is a highly reliable measurement of functional and hemodynamic severity of peripheral arterial occlusive disease. ${ }^{13}$ The test has been widely used for preoperative and postoperative evaluation and for measuring the response to therapeutic interventions for pulmonary and cardiac disease. It evaluates the global and integrated responses of all the systems involved during exercise. ${ }^{14}$

There have not been any studies on ABI using 6MWT as a screening tool in identifying PAD among diabetics with no symptoms of intermittent claudication.

\section{OBJECTIVES}

The objective of the study is to determine the frequency and severity of peripheral arterial disease among diabetics with no symptoms of intermittent claudication using the ankle-brachial index at rest and after the six-minute walk test.

\section{METHODOLOGY}

\section{Design}

This is a descriptive study; frequency is defined as the number of participants whose ABI at rest and after the 6 MWT were positive for PAD divided by the total population in the study, respectively.

\section{Study Population}

A total of 70 participants diagnosed with type 2 diabetes mellitus with no symptoms of intermittent claudication. The study was approved by the ethics committee and informed consent was obtained from the participants.

\section{Study Setting and Time Period}

Outpatient settings (Manila Doctors Hospital and Our Lady of Remedies Health Center Malate) taken from September to October 2011.

\section{Sample-Size Calculations}

The study required at least 67 subjects to achieve a $90 \%$ probability that the estimate is within the $10 \%$ margin of error from the prevalence rate of PAD among diabetics which is $17.7 \%$ among Asians. ${ }^{5}$

\section{Data Collection}

The study included participants more than 18 years of age diagnosed with type 2 diabetes mellitus from which informed consent was obtained. The participants did not have any symptoms of intermittent claudication. The following are the exclusion criteria: (1) individuals who have any form of lower limb revascularization, (2) critical limb ischemia, (3) recent history of cardiovascular or cerebrovascular injury and (4) individuals who are unable to perform the six minute walk test due to limb deformities or active arthritis.

\section{Ankle-Brachial Index}

A Handheld Doppler probe (Nicolet Vascular Pocket Doppler II; Nicolet Biomedical Inc, Golden, Colorado) was used to obtain the highest systolic pressures of the upper and lower extremities (brachial, dorsalis pedis, and posterior tibial arteries respectively). Only one technician performed the test. The ABI was calculated by obtaining the highest systolic blood pressure of the lower extremity divided by the highest systolic pressure of the upper extremity. Patients are then categorized as noncompressible, normal, borderline, mild-moderate and severe PAD.

In this study, the investigators used the current definition of computing the ABI.

The AHA guideline 2005 uses the following parameters in classifying the severity of PAD by ABI. ${ }^{15}$

$\begin{array}{ll}>1.30 & \text { - non-compressible } \\ 1.0-1.29 & \text { - normal } \\ 0.91-0.99 & \text { - borderline } \\ 0.41-0.90 & \text { - mild to moderate } \\ 0.00-0.40 & \text { - severe }\end{array}$

Based from Rooke et al 2011 PAD Guideline Focused Update, AHA 2005 Guidelines remains current. ${ }^{16}$

\section{Six-Minute Walk Test}

The 6MWT was performed indoors, along a long, flat, straight, enclosed corridor with a hard surface that is seldom travelled. Each participant was instructed to walk back and forth with usual pace walking. The walk course is 30 meters in length with a 180 degree turn-around points marked with a masking tape. An examiner observes each participant undergoing the test while noting for any discomfort.

The required equipments are: countdown timer (or stopwatch), worksheets on a clipboard, sphygmomanometer, hand-held doppler, ultrasound gel.

Patients were given instructions as follows: (1) To wear comfortable clothing and appropriate shoes for walking should be worn (2) The patient's usual medical regimen should be continued, (3) A light meal is acceptable before early morning or early afternoon tests, and (4) Patients should not have exercised vigorously within 2 hours before the test. 


\section{RESULTS}

In Table 1 , the mean age of participants is 60 years $(\mathrm{SD} \pm$ 12.2). Fifty-two were females $(74 \%), 18$ were males $(26 \%)$. Sixty-three percent were hypertensive, average systolic and diastolic blood pressure was $140 \pm 18.82$ and $82 \pm 12.39$ respectively. Sixteen (36\%) participants who were hypertensive are positive for PAD at rest. Of the $14 \%$ who were smokers, half were positive for PAD at rest.

\begin{tabular}{|c|c|c|c|}
\hline & \multicolumn{2}{|c|}{$N(70)$} & $\%$ \\
\hline Age in Years & \multicolumn{2}{|l|}{$60+12.2$} & \\
\hline Males & \multicolumn{2}{|l|}{18} & 26 \\
\hline Females & \multicolumn{2}{|l|}{52} & 74 \\
\hline Hypertension & \multicolumn{2}{|l|}{44} & 63 \\
\hline \multirow[t]{2}{*}{ Average $\mathrm{BP}$} & Systolic (SD) & Diastolic (SD) & \\
\hline & $140+18.32$ & $82+12.39$ & \\
\hline \multirow[t]{2}{*}{ (+) PAD } & Resting & 6MWT & \\
\hline & 16 & 15 & $(36)(34)$ \\
\hline Smoking & 10 & & 14 \\
\hline \multirow[t]{2}{*}{ (+) PAD } & Resting & 6MWT & \\
\hline & 5 & 4 & $(50)(40)$ \\
\hline
\end{tabular}

In Table 2, resting $\mathrm{ABI}$ revealed the following results: $1(1.42 \%)$ was non-compressible, 35(50\%) normal, $11(15 \%)$ borderline, and $23(33 \%)$ had mild to moderate PAD. After $6 \mathrm{MWT}$, results showed that $1(1.42 \%)$ was noncompressible, $31(44 \%)$ normal, $12(17 \%)$ borderline, $26(37 \%)$ had mild to moderate PAD. No participants were classified as severe at resting and after 6MWT.Among males $7(39 \%)$ were classified as mild-moderate at rest as compared to $9(50 \%)$ after the 6MWT. Among females 16 $(31 \%)$ were classified as mild-moderate at rest as compared to 17 (33\%) after the $6 \mathrm{MWT}$.

\section{DISCUSSION}

Based on this study, the frequency of PAD among diabetics using ABI seen at the outpatient department of Manila Doctors Hospital and Our Lady of Remedies Health Center was 33\% at rest and 37\% after the $6 \mathrm{MWT}$. This was higher than the Asian study which was $17.7 \%$ but almost comparable to the data done at Philippine Heart Center which was 30.6\%.7

Stenosis or obstruction is usually localized to large and medium-sized vessels of the lower extremities which are composed of atherosclerotic plaques. These plaques are the pathology in the development not only of the coronaries and cerebrovascular diseases but also with the aorta and arteries of the limbs (peripheral arterial diseases). ${ }^{17}$ Patients with coronary and cerebrovascular diseases have the increased risk of developing peripheral arterial disease.

Table 2 shows that 2 participants were classified as noncompressible. The ABI may underestimate the severity of PAD in patients with non-compressible outcomes due to arterial calcification most commonly in the presence of diabetes mellitus. ${ }^{18-19}$ This can be measured further by pulse volume recording (PVR) $)^{20-21}$ which is accurate up to $90 \%$ to $95 \% .^{22}$ More males were positive for PAD both resting and after the $6 \mathrm{MWT}$ than in females, this is probably due to age, gender and risk factors that are more commonly seen among males.

The frequency of PAD among smokers and those with hypertension is more than $30 \%$. Cigarette smoking is a major risk factor for PAD and increases the risk of PAD by 2 to 6 fold. On the other hand, hypertension increases pressure in arteries that damages arterial walls, leading to increased risk of claudication, 2.5 to 4 fold in men and women, respectively. ${ }^{7}$

Among the 70 patient volunteers, 8 (31\%) showed normal $\mathrm{ABI}$ at rest but a fall in the ABI after limb exercise. ${ }^{23-24}$ This can be explained by an increase in oxidant stress and injury to endothelial cells and fibers during repeated episodes of ischemia during exercise. ${ }^{25}$ On the other hand, 5 patients $(22 \%)$ had PAD at rest but showed a negative result after the 6MWT Possible explanations include improvement in endothelial function, skeletal muscle metabolism, blood viscosity and reduction of systemic inflammation. Another would be the increase in blood flow and oxygen delivery to the muscles during exercise. ${ }^{26}$

In the natural history of patients with PAD, 5 year mortality rate is $15 \%-30 \%$ and approximately one-third to one-half of patients with PAD have evidence of coronary artery disease. ${ }^{16}$ Hence, in these patients, it is imperative to reduce their risks for cardiovascular events and mortality. The management includes aggressive lifestyle and risk factor modification particularly optimal control for hypertension, diabetes and dyslipidemia.

These are the limitations of this study:

We may not see severe PAD in this study because the sample size of the estimate was based on the over-all frequency and is not powered to detect the differences in the severity of PAD.

Table 2. ABI classification of participants at rest and after 6MWT

\begin{tabular}{|c|c|c|c|c|c|c|}
\hline & \multicolumn{3}{|c|}{ Resting } & \multicolumn{3}{|c|}{ 6MWT } \\
\hline & Male & Female & Total & Male & Female & Total \\
\hline Non-compressible & 1 (5.55\%) & None & $1(1.42 \%)$ & None & 1 (1.9\%) & $1(1.42 \%)$ \\
\hline Normal & $9(50 \%)$ & $26(50 \%)$ & $35(50 \%)$ & $8(44 \%)$ & $23(44 \%)$ & $31(44 \%)$ \\
\hline Borderline & $1(5.5 \%)$ & $10(19 \%)$ & $11(15 \%)$ & $1(4.4 \%)$ & $11(21 \%)$ & $12(17 \%)$ \\
\hline Mild-Moderate & $7(39 \%)$ & $16(31 \%)$ & $23(33 \%)$ & $9(50 \%)$ & $17(33 \%)$ & $26(37 \%)$ \\
\hline Severe & 0 & 0 & 0 & 0 & 0 & 0 \\
\hline
\end{tabular}


Baseline diagnostic work-ups were not included in the data collection like fasting blood sugar, $\mathrm{HbA1c}$ and lipid profile which could probably benefit in determining control of diabetes and presence of other risk factors.

\section{CONCLUSION}

The frequency of PAD among diabetics with no symptoms of intermittent claudication using $\mathrm{ABI}$ seen at the outpatient department of Manila Doctors Hospital and Our Lady of Remedies Health Center was 33\% at rest and $37 \%$ after the 6 MWT.

Since this study only included diabetic patients, for further research, we recommend that the study population may be broadened to include hypertensive and dyslipidemic patients.

\section{Acknowledgements}

We would like to thank the following: Dr. Bernadette TumananMendoza, Dr. Noemi Pestano, Ms. Catherine Lagaya, Post Graduate Interns: Eloise Ann Laron and Maria Grethel Dimalala, for their wisdom, time, support and assistance in this study.

\section{References}

1. Raj Mohan L.N., et al. Peripheral arterial disease in communitybased patients with diabetes in Singapore: Results from a primary Healthcare Study. Department of Medicine, Khoo Teck Puat Hospital, Singapore. Annals of the Academy of Medicine, Singapore. July 2010; 39(7):525-(7)

2. Norgren, L et al. TASC II 2009 Epidemiology of Peripheral Artery Disease.

3. MacGregor AS, Price JF, Hau CM et al. Role of systolic blood pressure and plasma triglycerides in diabetic peripheral arterial disease. The Edinburgh Artery Study. Diabetes Care. 1999, 22:453-458

4. Kallio M, Forsblom C, Groop PH et al. Development of new peripheral arterial occlusive disease in patients with Type 2 diabetes during the mean follow up of 11 years. Diabetes Care 2003;26:1241-5.

5. Sy, R. et al. Abstract. PAD-Search. Diabetes Res Clin Pract. Apr 2007. 76(1):82-92.

6. Bowlin SJ, Medalie JH, Flocke SA et al. Epidemiology of intermittent claudication in the middle-aged men. Am J Epidemiol.1994; 140: 418430.

7. Dans, A. et.al., "National Nutrition and Health Survey: Atherosclerosis-related diseases and risk factors". Philippine Journal of Internal Medicine, 2005; 43:103-115.

8. PHILPAD Group 2000. Prevalence of PAD: NCR Study.

9. Gallardo, MD et al, The severity of peripheral arterial disease by Ankle-Brachial Index Determination, predictor of the severity and Jeopardy score of coronary artery disease Philippine Heart Center, PJC Vol. 37 No 1 January to June 2009 page 10-16.

10. Norgren, L, Hiatt WR, Dormandy JA et al. Inter-Society consensus for the management of peripheral arterial disease (TASC II). Eur J Vasc Endovasc Surg. 2007 ; 45 (Suppl S) : 5-67.

11. Burns P, Gough S, Bradbury AW. Management of peripheral arterial disease in primary care. BMJ 2003; 326:584-8.

12. Olin J.W. The clinical evaluation and office-based detection of peripheral arterial disease. In: Hirsch AT. Olin FW, eds. An OfficeBased Approach to the Diagnosis and Treatment of Peripheral Arterial Disease 1: The Epidemiology and Practical Detection of Peripheral Arterial Disease. Am J Med. Continuing Education Series. Bellmead, NJ: Excerpta Medica, Inc.,1998:10-17

13. Montogomery P.S., Gardner A.W. The clinical utility of a six-minute walk test in peripheral arterial occlusive disease patients. J Am Geriatr Soc. 1998 Jun; 46(6):706-11

14. ATS Statement: Guidelines for the Six-Minute Walk Test. Am J Respir Crit Care Med. 2002, 166: 111-117

15. Hirsch A, Haskal ZJ, Hertzer N. et al. ACC/AHA 2005 Guidelines for the Management of Patients With Peripheral Arterial Disease (Lower
Extremity, Renal, Mesenteric, and Abdominal Aortic): Executive Summary A Collaborative Report From the American Association for Vascular Surgery/Society for Vascular Surgery, Society for Cardiovascular Angiography and Interventions, Society for Vascular Medicine and Biology, Society of Interventional Radiology, and the ACC/AHA Task Force on Practice Guidelines (Writing Committee to Develop Guidelines for the Management of Patients With Peripheral Arterial Disease): Endorsed by the American Association of Cardiovascular and Pulmonary Rehabilitation; National Heart, Lung, and Blood Institute; Society for Vascular Nursing; TransAtlantic Inter-Society Consensus; and Vascular Disease Foundation. J Am Coll Cardiol. 2006; 47(6):1239-1312.

16. Rooke T, Hirsch A, Misra S et al. 2011 ACCF/AHA Focused update of the guideline for the management of patients with peripheral artery disease (Updating the 2005 Guideline). J Am Coll Cardiol. 2011; 58(19):2020-2045

17. Harrison's 17th ed. Principles of Internal Medicine p1568-1569.

18. Quigley F.G., Faris I.B., Duncan H.J. A comparison of Doppler ankle pressures and skin perfusion pressure in subjects with and without diabetes. Clin Physiol 1991; 11:21-25.

19. Taguchi J.T., Suwangool P. "Pipe-stem" brachial arteries: A cause of pseudo hypertension. JAMA 1974; 228: 733.

20. Ouriel K, Zarins C.K. Doppler ankle pressure: An evaluation of three methods of expression. Arch Surg 1982; 117: 1297-300.

21. Kempczinski RF. Segmental volume plethysmography in the diagnosis of lower extremity arterial disease. J Cardiovasc Surg 1982; 23: $125-29$.

22. Darling R.C, Raines J.K, Brener B.J, Austen W.G. Quantitative segmental pulse volume recorder: A clinical tool. Surgery 1972; 6: 873-87.

23. Symes J.F, Graham A.M, Mousseau M. Doppler waveform analysis versus segmental pressure and pulse-volume recording: Assessment of occlusive disease in the lower extremity. Can J Surg. Jul 1984; 27(4):345-347.

24. Carter S.A. Response of ankle systolic pressure to leg exercise in mild or questionable arterial disease. N Engl J Med 1972; 287: 578-82.

25. Ouriel K, McDonnell AE, Metz CE, Zarins CK. Critical evaluation of stress testing in the diagnosis of peripheral vascular disease. Surgery 1982; 91: 686-93.

26. Melov S, Shoffner JM, Kaufman A, Wallace DC. Marked increase in the number and variety of mitochondrial DNA rearrangements in aging human skeletal muscle. Nucleic Acids Res. 1995; 23:4122-4126.

27. Stewart KJ, Hiatt WR, Regensteiner JG, Hirsch AT. Exercise training for claudication. N Engl J Med. 2002; 347:1941 